Article

\title{
Racial Exclusion in the Online World
}

\section{Rebecca J. West ${ }^{1, *}$ and Bhoomi K. Thakore ${ }^{2}$}

1 Department of Sociology, Loyola University Chicago, 1032 W. Sheridan Rd., Coffey Hall 4th floor, Chicago, IL 60660, USA

2 Feinberg School of Medicine, Northwestern University, 420 E. Superior St., Rubloff 12, Chicago, IL 60611, USA; E-Mail: Bhoomi.thakore@northwestern.edu

* Author to whom correspondence should be addressed; E-Mail:westrj@gmail.com; Tel.: +1-312-912-5670.

Received: 11 March 2013; in revise form: 25 April 2013 / Accepted: 7 May 2013 /

Published: 24 May 2013

\begin{abstract}
As the internet has become an integral part of everyday life, it is understood that patterns of racial stereotyping and discrimination found in the offline world are often reproduced online. In our paper, we examine two exclusionary practices in an online environment for adult toy collectors: First, the exclusion of non-white individuals who are expected to form immediate friendships with other non-white members; and second, the essentializing of racial issues when concerns over the lack of racial diversity in the toys are discussed. This dismissal is often directly connected to non-white members' decisions to no longer participate, resulting in a new form of segregation within virtual space.
\end{abstract}

Keywords: racism; whiteness; exclusion; Internet; American Girl; online message boards

\section{Introduction}

"Hi, TansyTen! Welcome to the Playhouse... You should look around for Sandrine10 and MskratMlly. I think that they will be good friends for you!"

In most online communities, moderators have the responsibility of both welcoming people and controlling the environment of the online space. These two tasks are often accomplished simultaneously. In the message above, a moderator has suggested that TansyTen, a new member of this community, reach out to two more established members. On the surface, this is a very welcoming gesture, in that it helps the new member make connections with other users. However, a little context 
reveals a more complex situation: In her introduction to the forum, TansyTen identified herself as a Black woman. The two members suggested by the moderator are also Black. As TansyTen said later during a one-on-one interview,

"It's like, here I am, and I said I was Black in my profile...and (the moderator) thought I'd be friends with these other people, but we don't have anything in common except we're Black...I mean, really, I mean, it's hard to find Black people on the internet but I can find them on my own. Like, am I not supposed to talk to the white people?"

The opening interaction took place in an online forum where adult women come together to discuss the collecting of American Girl dolls, is a consciously multi-ethnic and multi-racial product line. In the forum the role of race in the success or failure of these products is a frequent topic of conversation. Through these public conversations, other racial processes come to the forefront. Thus, this forum provides a rich site to examine the power of race in the virtual world.

The actions seen in the case above are an example of boundary policing in virtual spaces. It is well known that the internet remains segregated both in access and within the interactions. What is of deeper sociological interest is the question of why this segregation occurs. By examining the interactions within a specific virtual community, we can begin to understand how participants in online spaces create and maintain racial boundaries. We argue that this segregation is maintained by both active and passive means, resulting in a space where discussions of race presuppose a social order in which white identity is idealized and normalized.

As the World Wide Web continues to develop, so too does the ease in accessing information online. Today, more and more people participate in multiple forms of virtual communities. Forums, message boards, and social networking sites are part of the social fabric around the world. People participate in these types of forums for many reasons: information seeking, problem solving, professional obligations, and, of course, for social contact. These online worlds provide a place for their users to join with others who share a common interest, regardless of social or geographic location. Additionally, these worlds provide another "socially manifest" space wherein users may consume, create, and define the texts that shape their interests. For fans, this is particularly salient [1]. As Kozinets has pointed out, these virtual social groups have a tangible influence on the people who participate in them, and their participation influences many aspects of their behavior both on and off line [2]. As spaces of significant social interaction and information transmission, the extent to which online interactions shape ideologies must be examined.

In this paper, we take a deep look at how online patterns of discussions create racialized boundaries, and discuss how these boundaries reproduce some of the inherent problems with inter-racial interactions in the offline world. Through the use of virtual ethnographic observation, survey data, and interviews, we will identify those exclusionary practices that are alive and well in the supposedly egalitarian and utopian space of the online world. We identify two types of boundaries and define them as exclusionary and essentializing. In this paper, we begin with a brief overview of relevant literature and the American Girl line of products, and then describe and discuss our research methodology. In our analysis, we present the ways in which some of the interactions in this online forum correspond to the established sociological concepts of racial perceptions, racialized interactions, and colorblind 
racism. We conclude with the takeaway points of our findings and discuss how these data provide a new understanding of how racialized social processes operate online.

\section{Literature Review}

In the United States, social interactions are informed by the specific stereotypes associated with racial and ethnic minority groups. These stereotypes are informed in part by racial formations - the social, political, and economic factors that determine the social standing of racial/ethnic minorities [3]. On one hand, the critique of racial formations theory is that it fails to acknowledge the systemic nature of racism and prejudice [4,5]. While it may seem that race relations have improved today, critical race scholars would argue that U.S. society has shifted now to a more covertly racist and colorblind society in which segregation exists but stereotypes remain [6-8].

Colorblind racial attitudes play out in all forms of interaction. As Bonilla-Silva suggested, most whites tend to express one or more of the four frames of colorblind racism: abstract liberalism (associating political and economic liberalism to racial issues), naturalization (explaining racial differences as natural phenomena), cultural racism (invoking arguments of cultural difference to explain inequality), and minimization (minimizing instances of discrimination) [6]. Not only do these frames inform individual perceptions about racial inequality, but they can also inform the kinds of interactions that occur between whites and non-whites. These colorblind frames also play out in the online world. For example, individuals who practice overt forms of discrimination (as with the example in the introduction) invoke cultural racism and minimization to explain their behavior away. This dynamic is particularly relevant when factoring in the "digital divide" and the demographics of the online population.

Historically, the digital divide has been relevant for identifying and understanding those individuals who are online. According to a 2000 survey released by the Pew Internet and American Life Project, it was estimated that about $53 \%$ of adult Americans did not have internet access; with $57 \%$ of this group has no interest in going online. In 2000 , only $50 \%$ of whites, $44 \%$ of Hispanics, and $36 \%$ of Blacks had internet access [9]. In a follow-up 2012 survey, it was estimated that the number of adult Americans who did not go online dropped to $22 \%$. By then, $80 \%$ of whites, $71 \%$ of Blacks, and $68 \%$ of Hispanics used the internet [10]. While these numbers indicate that internet usage has increased among adult Americans, and increased among particular racial/ethnic groups, it is evident that some racial inequalities still exist. When taking into account the demographics of the United States, comprised of $72.4 \%$ whites, $12.4 \%$ Blacks, $16.3 \%$ Hispanics, and $4.8 \%$ Asians, it is apparent that whites continue to dominate online worlds as they dominate offline social worlds.

However, the argument that non-whites are at a disadvantage because of this supposed digital divide is problematic in its assumption that these individuals are at a technological disadvantage [11-13]. This supports the notion that minorities are secondary to whites in all arenas, particularly those that have to do with access to knowledge and education. As Daniels suggested, this phenomenon of racism through the internet puts the onus on minorities to identify those instances of racism. This argument also aligns with Stuart Hall's work on the spectacle of the other, which not only helps to create a community of whites, but also serves as a way for a community to exclude non-whites [4,13,14].

In the same ways that white supremacist ideology dominates social interactions, so too will the expression of these ideologies in online interactions maintain the marginalization of non-whites in the 
online world [15]. One example of this is how the frames of colorblind racism are activated in virtual spaces. This activation may be direct, where racist ideas are expressed under the excuse of humor or the attitude that such statements do not apply to "good" minorities, or covert, where the racial attitudes are muted in the guise of "this mattered in the past, but not today" [16].

While internet communities can be a powerful place for establishing and re-affirming ethnic solidarity [17], these same forces can be used to work toward exclusion of others. In a study of white supremacist networking, Daniels found that virtual networking has allowed for the ideologies of white supremacy to cross national and international borders [4]. This re-entrenchment of racist ideologies becomes a major force creating a hostile environment that is exclusionary to racial minorities.

As Myers found, the ways in which groups of individuals engage in racialized conversations known as racetalk maintain racial boundaries and reinforce racial perceptions [18]. A similar kind of racetalk occurs online, but in a more public way. For example, individuals who express their particular feelings directly to minority users about whom they should socialize with in an online forum reinforce a public form of racetalk that ultimately serves the same ideological purpose. Specifically, this kind of expression or "talk" imposes white supremacist ideologies regarding the kinds of people with whom whites can interact and not interact, and discourages any interest in reaching across racial boundaries. As we argue, these dynamics are reproduced in the interactions that occurred among our sample of American Girl consumers in their online discussions.

Race is not the only place where a digital divide may exist on the internet. Early studies of internet culture noted that access to the internet was heavily split along gender lines through the mid to late 1990s, with men dominating the internet both in terms of access and of use [19]. However, this gap diminished by 2001, when socioeconomic status became the more relative determinant of internet access [20]. While it is assumed that men are more likely than women to use the internet, it is important to acknowledge that the internet is not a monolithic world. In fact, there are "many internets"-virtual locations created for social interactions by a group of people who develop a sense of community and, more importantly, a sense that they can accomplish something together within that specific virtual space [21].

As scholars have suggested, gender socialization is strongly influential on patterns of communication. The recognized gender of participants in online communities can also influence the style of communication within the community. An early study found that in online communities where the majority of members were men, the communication style was dominated by "fact oriented language" and "calls for action." In those internet spaces that are implicitly or explicitly marked as feminine, identifiable "feminine" styles of communication predominate [22]. These spaces allow women a place to challenge the stereotypical ideas of feminine communication style. For example, women in these spaces tend to verbally confront other members, use profanity, and focus on instrumental rather than emotional language $[23,24]$.

On the other hand, in communities where the proportion of men to women was more equal, the community members of both genders used more "self-disclosure" and attempted to reduce tension among members. However, the men were not shown to display more aggressive or confrontational language, and women were not engaged in apologetic or opinion-based language behavior [25]. Gendered styles of communication may also be deployed strategically in spaces that are either marked as masculine or are mixed-gendered. For example, identified women users may adopt masculine styles 
in an attempt to have their contributions to the community taken as "seriously" as that of identified men users [26].

These findings bring up an important caveat to studying gender on the internet. Specifically, online gender identity is dependent on the user actively disclosing their gender. Even when a user chooses or is required to display a gender, there is no guarantee that the gender they display online is the same as that displayed offline. Indeed, gender may be used as a mask, a tool of expression, and a new arena for play [27]. While the empirical work on gendered differences in communication have over-emphasized the difference and perpetuated negative gender stereotypes [28], the debates over gender on the internet are important to note.

\section{American Girl}

"American Girl" (AG) refers collectively to a line of eighteen inch vinyl play dolls, appropriately scaled accessories, and books aimed at girls aged eight to eleven. Diamond et al. described the company as a "\$436 million doll empire" that gains its appeal by combining immersive retail and catalog environments [29]. American Girl sells not only specific representations of "girlhood," but promotes the values and cultural norms associated with middle-class white American culture.

The company debuted in 1986 with a line of three "historical" dolls, all white, each with a distinctive story. As the years have progressed, the company has expanded that line to twelve historical dolls covering two hundred and fifty years from Kaya, the Nez Perce girl from 1754, to Julie, the white latchkey daughter of a divorced mother in 1974. These dolls have explicit racial and ethnic identities, ranging from American Indian to Swedish to African American. Each of these dolls comes with a series of books that construct a historically and culturally appropriate narrative. The girl consumer can purchase accessories that illustrate events and items in the stories (such as clothes, furniture, dishes and sports equipment).

In addition to this historical line, the company has two other product lines that are relevant to our study: the "MyAG" line of contemporary dolls, and a "Limited Edition" series, also of contemporary girlhood. Within the "MyAG" line, the consumer is invited to choose a doll from a range of options in terms of physical appearance, including the shape of the face, skin tone, hair color and texture, and eye color. Unlike the historical line, these dolls do not have a set narrative; the girl consumer is invited to create her own narrative. That narrative can be expanded on by purchasing various accessories - everything from horses to barbecue grills.

We stated in the introduction that American Girl is "consciously multi-racial and multi-ethnic." This fact is particularly demonstrated in the company's third line of products, the "Girl of the Year" (GotY) series of dolls. This line combines the contemporary focus of the MyAG line with the narrative element of the historical line. As limited edition collectibles, these dolls come with small collections of accessories and furniture that correspond with elements of their stories. Each doll also has some unique aspect in terms of physical appearance: a different hair style, color of eye, or even a completely new head shape. At the time of writing, American Girl has created eleven GotY dolls, three of which have had explicitly non-white racial and ethnic identities. The remaining characters have been, presumably, white. It should be noted that while race and ethnicity are explicitly discussed within the text of the books for the non-white dolls, race is never mentioned for the other seven. 
In the collecting forum, members have made a variety of comments that exemplify this practice of assuming whiteness as the unmarked, normative category. For example, the original face sculpt (mold) introduced by American Girl in 1986 was then and is now only available in the lighter shades of vinyl. This face is referred to by collectors as the "classic mold." The other face molds introduced later are referred to by either the name of the character or the race that the face represents (i.e., the "Addy" or "African-American mold"). Again, whiteness is implied, while non-whiteness is explicit and Othered. American Girl's selections of historical and modern images that are memorialized in doll form construct a narrative of the fulfillment of the American dream: assimilation, middle-class achievements, and symbolic diversity [30]. Although there are minority, lower-class, and immigrant characters, the ultimate goal (of the dolls) is to reach a higher level of achievement within the system, rather than to challenge it.

While American Girl is a set of toys aimed at preteen girls, it is important to note that children's consumption is mediated through their family structure. Generally, parents and other caregivers must provide the opportunity and means for children to consume any item. The significant of parents' beliefs in the selection of children's toys is often overlooked, not only in the analysis of the American Girls collection, but also in the analysis of the consumer toy market [31]. In guiding their children's consumption, parents have the opportunity to challenge or reinforce pre-existing ideologies about girlhood, America, and race.

American Girls are not "just dolls;" they are a specific set of consumer goods that are both produced by and productive of American ideology [32]. Consumers' interactions with American Girl are significant for the study of race because the products themselves are explicitly racialized. This racialization is not merely that the dolls fit particular stereotyped expectations of appearance; it is also expressed specifically by the literature produced by the American Girl company [33]. Because of this, these products invite discussions of race without outside provocation - that is, because race is made explicit in the products themselves, the social space for a discussion of these issues is created. This condition of possibility is where new social forms may emerge or old ones may be reified [34]. In this study, we have chosen to examine adults who collect these products. In addition to purchasing these products for their children, these collectors interact with these products for their own entertainment and use them as the means towards forming friendships with others. Although women are recognized as a consuming group - $85 \%$ of all consumer purchases are made by women - the interpersonal meaning of their leisure activities remains under studied [35]. With this analysis, we are seeking to examine the intersections of leisure-time consumption, women's social networks, and racial ideology.

\section{Methods}

Our project focused on members of a specific online forum, which we have identified as "The Playhouse." This forum was established in 2006 and has more than 4000 registered members. Of these, an average of 300 members log in daily, with an average of 497 new comments posted on a daily basis. Between November 2009 and January 2010, the members of this forum were offered a survey that asked for demographic information and personal collecting and online forum behavior. Of the 297 members who began the survey, 285 members completed at least $75 \%$ of the questions. The demographics of the community are presented in Table 1. Overall, they establish that the forum 
was predominately women (95\%), almost entirely white $(91 \%)$, and had a median income in the $\$ 40,000-\$ 59,999$ range.

Table 1. Demographics of the Playhouse community members.

\begin{tabular}{ccc}
\hline Question & Responses & Percentages \\
\hline \multirow{3}{*}{ Gender } & Women & $94.5 \%(309)$ \\
\cline { 2 - 3 } & Men & $3.7 \%(12)$ \\
\cline { 2 - 3 } Race \\
\cline { 2 - 3 } (multiple responses \\
\cline { 2 - 3 } allowed)
\end{tabular}

The Playhouse group is what Kozinets would classify as an "electronic bulletin board" [2], in that it focused on a specific product. In fact, $93.4 \%$ of members reported that they used the forum specifically to find out information about new American Girl products. The Playhouse does have some features of a "chat room", but discussions there were limited to related American Girl products. Additionally, the relationships in the Playhouse are much more tangible to members - $30.7 \%$ of the members reported that they view the other members of the forum as either casual or close friends.

In addition to the survey, we used virtual ethnography to examine the actual interactions between the members. This observation period extended from 2009 to 2011, and included an in-depth review of the community archives that date back to spring of 2006. In particular, we analyzed the "Introductions" section of the forum in order to establish the racial demographics of regular users. One of the authors (West) had established membership in 2007 and actively participated in the community. This long-term membership contributed to rapport between researcher and the subjects, and also helped contribute to the excellent survey response rate. As well as including observations of the public interactions on the forum, we also include analysis from interpersonal messages shared with us by members. 
For the purposes of this research, the archives of the community were treated as transcripts. As in traditional ethnography, intervention of the researcher can unintentionally alter virtual community interactions. Thus, our analysis of the public forum interactions only includes those threads where the researchers were not participants. Virtual ethnography was a particularly appropriate method for this study not just because it took place online, but because it allowed us access to a group that may have been otherwise unreachable [2]. But, this location is not a convenience sample - as an online gathering of fans of American Girl, the Playhouse board becomes a socially manifest space, one with no physical location [1]. The only way to investigate this arena is to engage in participant-observational methods inside the community.

While the internet is often viewed as public space and therefore not subject to privacy considerations, the fact that this forum required participants to register with the moderator and gain approval for membership suggests that the members may have held a different view of the space. Accordingly, we sought permission from the forum moderators to conduct our research. When this was granted, members of the forum were offered the opportunity to opt out of having their forum contributions included in this study. (No members took advantage of this offer). The name of the forum, the usernames of the participants, and any identifiable information has been altered to protect anonymity, following the practices suggested by Hines [36]. All other standard practices for anonymity were followed as well. All research methods were approved by the Institutional Review Board of Loyola University Chicago.

Finally, interviews were conducted with survey respondents who volunteered for further contact. Twenty-three interviews were conducted in all. Two of these interviews were with community moderators, while the rest were with members who had participated in the community for at least six months. Sixteen of the interviewees were white; four were African-American; two were Asian-American; and one was Native American. Both moderators that were interviewed were white women.

It should be noticed that children (or explicitly, girls) as consumers of American Girl products do not necessarily recognize or discuss the racial questions present in these objects. Acosta-Alzuru noted in her dissertation that while the girls' mothers emphasize the importance of the books and historical narratives that accompany American Girl dolls, the girl consumers rarely enact these storylines or even read the books [37]. Our study population is focused on adult women - 50.9\% of whom are mothers — and they also emphasized the importance of the American Girl narratives. About $40 \%$ of our survey population indicated that their enjoyment of the story that came with a doll was "somewhat important" when they chose to purchase the doll, while 55.6\% said that looks of the doll were "not important at all." While a slight difference, our respondents do appear to emphasize the importance of the stories over the appearance of the dolls. The narrative aspect of American Girl was also noted as something that justified the high price point of the products. While $61.9 \%$ of respondents said that the prices were "high" and $12.7 \%$ said the prices are "very high," $94.1 \%$ of respondents offered a comment that the quality of the products, especially their educational aspects, justified the prices. (Perhaps unsurprisingly, none of the collectors felt the prices were either "low" or "too low.") 


\section{From Integration to Segregation: A Timeline}

It can be difficult to establish the racial diversity of an online space, particularly a "general" one such as The Playhouse where members are not expected to be of any particular background. While our survey data established that that $18.1 \%$ of the members of the forum identified as non-white, this number does not provide much insight into people's actual participation. After further investigating the "Introductions" forum, we established that $27 \%$ of those who posted descriptions of themselves identified as explicitly non-white. Using this information, we were able to trace the pattern of participation by racial minorities over time.

When the forum was created in spring of 2006, many of the original members had been members of other online communities, creating a core group of members who were already generally familiar with each other's identities and interests. Excluding the creator of the community and the three people named as moderators, there were 35 original or core members. Many of these original members used the same user names they were known by in the previous communities. Even though these core members already knew each other, they wrote introductory posts as a courtesy to new members. The racial composition of the community at that point in time was very similar to what it was at the time we conducted our survey, with a slightly higher percentage of members identifying as non-white in their introductions (six out of the 35 "core" members, or 17.2\%). The forum has had at different times between four and seventeen moderators that have had different responsibilities, including directing discussions, organizing the various sections of the boards, arranging offline activities for members, and directly enforcing the rules of the forum. For this analysis we have focused on the actions of the four moderators of the general discussion forum. These moderators were all women; three of them identified their race as white, while the remaining moderator chose not to disclose her racial identity.

In December of 2006, this changed. At this point, another American Girl collecting forum changed its membership requirements and rules for participation. As a result, many members of this second community were either banned or chose to leave, and moved to The Playhouse as an alternative. While the actions in the other community are not part of our analysis (consent to conduct research in this second community was sought in 2009 , but the request was refused), many of these new members expressed their feelings of being targeted by the rule changes as racial, religious, and sexual minorities in that community, and turned to The Playhouse as a more "liberal" or inclusive forum. At this point, the number of self-identified racial minorities increased slightly, with $22.5 \%$ of the members indicating their non-white racial identity in their introductions.

However, the Introductions only tell one part of the story of community activity. Posting an introduction to the board is how a member moves from a "lurker" (non-participating member) to an active status. Lurking is a common and expected internet behavior where a hopeful member may observe without contributing until they are familiar with the community norms and introduce themselves when they have some confidence that they will not break a norm [38]. However, a member who introduces themselves does not always become an active participant and, as we later discuss, active participants may also drop out of participation.

Having determined members' racial identities, we investigated their patterns of participation throughout their membership in the community. There can be many reasons why a member will choose to stop participating in a community-including life events, loss of interest in the topic, or 
moving to a new forum. But when race is considered, it became clear that active non-white members were more likely than active white members to end their participation in this forum. For example, at the time of writing, only two of the original core non-white members of the community were still participating, whereas 18 of the 29 white members were. Further, while $26 \%$ of the white members who joined after problems with the second community participated beyond their first introductory post to The Playhouse, only $7 \%$ of the non-white members participated at the same level. It is apparent that these discrepancies are based on the exclusionary practices by white members toward non-white members.

The non-white members of the Playhouse did not end their interest in American Girl collecting or their allegiance to online communities focused on their hobby. Instead, they moved on to create other forums in other venues, such as through personal blogs, Facebook groups, or self-created Wikis. Unlike the Playhouse, these new communities are not known as central hubs of activity for American Girl. As TansyTen, the moderator of one of the new groups that is discussed later in this paper, these new groups are places for those who had explicitly been excluded from and discriminated against in the Playhouse.

\section{Racialized Identification and Friendship "Steering"}

As Nakamura has extensively discussed, the establishment of an individual's racial identity in an online space is determined by two factors: how much an individual chooses to share, and the interpretation of that information by their audience $[39,40]$. Both of these aspects are at play in the Playhouse forum. When a person joins the community, they are expected to make a post that will serve as their introduction to the community. These posts share many common themes: the individual will mention how they first became interested in American Girl, discuss why they sought out the forum, and provide some personalizing details such as geographic location, their profession, or their marital status.

Racial and ethnic identity is one of the personalizing details that members sometimes include, as in the example below,

"Hey guys! I'm sure many of you have seen me around the board already, but I figured I'd make a 'formal' introduction. I'm Anju, short for Anjana, although I also go by Anu (it's my 'daknam', or informal name at home). I am Indian-American, (...) I was born in (New England) but I grew up (...) about a half an hour away from Williamsburg, VA (Felicity's hometown!) (Posted June 2007)"

After reviewing the introductory posts on the forum, a clear pattern emerged. The only members who mentioned their race were those who are non-white. To be clear, not every non-white member discussed their racial identity in their introduction, but absolutely no white members thought this information was important enough to establish who they were in the forum. Introductions from white people were more likely to resemble this example,

"I have a 2 year old daughter and ever since I knew she was a girl (about 5 months into my pregnancy) I have been collecting AG dolls. I wish they had had these dolls when I was young, I had Barbies but these dolls are so much cooler and I love the books. I am hoping to start making clothes for them, too. I can't wait until my daughter gets a little older so she can play with them with me! (My family thinks I'm nuts, but I'm used to that!) (Posted December 2006)" 
This pattern is hardly surprising. White people often do not consider themselves to have any race at all. This follows directly on the idea of whiteness as a default racial identity [8,41]. In fact, this pattern echoes American Girl's own practices of identifying the race of their characters. The introductions posted on this forum serve as more than an individual's entree in to a community-they become the basis for how others, particularly moderators, interacted with the individual. As our introductory respondent TansyTen explained, the mention of race in her profile led moderators to steer her toward the other Black women on the forum, without any knowledge of other similar interests or collecting choices.

Given that these introductory posts are short, there could be an argument that the "steering" of people is a result of the moderators having to work with the few details they have. However, the introductory posts are not the only information that the moderators (and others on the boards) have about the members. They are also aware of what dolls the person collects and what discussions the member is more likely to participate in. TansyTen's collecting interests were on the contemporary line of dolls, and she felt strongly that she would only purchase dolls that represented Blackness to her. The two members she was referred to both preferred the historical dolls, and had repeatedly noted that they had a preference for the dolls with white features. In other words, while TansyTen and these other members are both interested in American Girl, they have radically different preferences for the various products.

Unfortunately, the opportunity to ask a moderator about how they chose to suggest friends for new members did not present itself. Whatever the specific motivation of the moderators was, it is important to note that only the members of color who were interviewed mentioned receiving such introductory messages - white respondents did not. Regardless of how the moderators intended their actions, the non-white members of the community perceived them as racist and exclusionary.

\section{Community Discussion and Essentializing}

American Girl as a company has consciously created an impression of racial and ethnic diversity, but the actual product line-up does not support this image. While the average consumer may not be aware of the intricacies of the company's history, the collectors are. They have dedicated much time to their hobby, and thus recognize what the company has done and has failed to do.

One such failure is the fact that American Girl has not yet created a GotY character who is African-American. An oversight obvious enough to have received attention in the popular press, this "missing" representation is discussed regularly every year within the community. The discussions about this oversight generally begin in the summer, when members look to see if book covers have been made available to retailers, or if there are leaked products available on eBay. The discussion generally reaches its peak in the fall when American Girl releases some early information on its website or to the national press. The conversation subsides when the new doll is released in January, and the pattern repeats. These discussions in the forum center on the questions of whether an African-American character would be economically viable for the company. The members of the community overwhelmingly expressed a desire for a Black GotY doll in their forum posts, a desire that was also reflected in responses to the survey of members - almost $90 \%$ of survey respondents expressed the hope that American Girl would release a Black limited edition doll in the near future. 
The fact that this discussion happens on an annual basis is surprising because the majority of forum members surveyed did not participate in the discussions. In the survey, $86.7 \%$ said they read the discussions centered on race, only $36.6 \%$ said they participated. This was supported with the analysis of the forum archives, which showed that the conversation about racial representation in American Girl was maintained by a core group of participants.

However, the explanation of the choice to not participate, and the perception of these discussions, reveal a distinctly racialized pattern. White community members repeatedly expressed a feeling that discussions about race were unpleasant, uncomfortable, or something that was irrelevant to the topic of doll collecting and should be stopped. As these white members stated in their survey comments,

"I find (the discussions) shallow. While I am all for racial equality among people, I will not buy a doll with features I do not find attractive just to prove that I'm not a racist."

"They're fucking annoying. Seriously. I'm all for more diversity, but a lot of time I feel like the Addy love is solely countering racism, and sometime the arguments seem racist against white collectors."

"I just want them to shut up. There's a new thread every few days about race and it makes me want to leave."

On the other hand, non-white survey respondents had a different interpretation. While they also said that these conversations could be uncomfortable, they also stated that they enjoyed the conversations because they allowed them a chance to discuss issues they saw as problems. As some of these non-white members said in their survey comments,

"They tend to be very frustrating. Usually someone says something cluelessly insensitive and continue to be clueless throughout, and nobody really stops them."

"I seem to most often post only to correct others' misinterpretations of a race or culture."

"I participate. And often people don't like my opinions b/c I am not white washing anything making it all peaches and cream.”

In addition to these different perceptions of the conversation, non-white survey respondents were more likely to state that they used to participate in the racial discussions but have since stopped. While $45 \%$ of non-white respondents reported no longer participating in these discussions, only $15 \%$ of white respondents stopped participating. As one non-white respondent said,

"Not anymore! Not since I was told my own ethnic identity does not exist...It was just one person but they were pretty offensive in their complete cluelessness..."

The survey data provide an interesting look at the overall attitude toward racial discussions in the Playhouse community. When the responses are viewed without controlling for race, there is a generally negative attitude about racial discussions, and an overall wish that the discussions would stop. The actions of the community moderators tend to reflect this wish. While moderators maintained a rather hands-off approach in most topic threads, rarely stepping in to guide the discussion, they became more involved in those threads where the discussion centered on race. Discussions where race was introduced were often moved from the main discussion area to an "off topic" section (where participation was less active and threads tended to end). Members were often told to look for past 
discussions on the topic that have been "merged" (combined with similar threads) and "archived" (placed in an area of the board were further discussion is not permitted). Most telling was the frequency of warnings from moderators about content - present in only 3\% of general topics, but 97\% of race topics.

However, as our analysis shows, the opposition to discussions of race is not equally shared among members of the community. When the race of the respondents is considered, it is clear that the opposition to discussions of race comes primarily from the white community members. In responding to this community wish, the moderators are indeed responding to a majority - however, that majority is explicitly white. By maintaining the perspective of the white members only, non-white members are not permitted in the discussion and excluded as a result.

\section{Finding New Boundaries}

During a discussion about American Girl's new products in December 2010, one member noted the absence of people of color in the discussion. As she posted,

"Where's TansyTen and Anju and (another member of color)? They haven't been around much and I would like to hear what they have to say."

A moderator stepped in to say that members' comfort levels with posting will change depending on personal circumstances, and that if she (the member) was missing a particular person, she should try to contact those members in a private message.

However, this public response tells only part of the story. Two of the members that were named had left the community and terminated their accounts, which they discussed in their follow-up interviews. The third member had received a lifetime ban from the moderators of the community for her comments during a previous discussion on race. These three members, all women of color, had moved on to create another forum to discuss their interests. This new forum was small, open by invitation only, and, unlike the Playhouse, was made up predominately of women of color. TansyTen was one of the founding members and the main moderator.

During our interview in May 2011, TansyTen explained why she had decided to create the forum,

"It just got old, you know. Like all the people and it was exhausting. So we get together over here and we still get to talk about the same issues, but...um....we don't have to explain them over and over and over again. You know?"

This phenomenon, of marginalized groups forming their own communities has sometimes been referred to as "self-segregation" [42]. Indeed, this narrative was present within The Playhouse. As one of the Playhouse moderators said in another discussion on race,

"I can attest that it's mainly our active posters who respond and not many non-posting lurkers.

I'd personally love to see more diverse opinions offered by our lurkers, but everyone has their own comfort level about posting and becoming part of a large community like The Playhouse, so it is what it is in that regard. (Posted January 2009)"

As this comment exemplifies, the moderators in the forum perceived the issue with non-contributing members or members choosing to leave altogether as an individual issue, rather than as something that 
arose because of the problematic nature of the interactions that members had within the group. But, as Villalpando discussed, the formation of such race-specific communities outside of established institutional frameworks is not an offensive action by non-whites, but a defensive one [43]. Having felt silenced and excluded within the larger community, the non-white members chose to leave and established a new online space where they felt comfortable. Again, as TansyTen explained,

"Um, like, it's not that there aren't whites here (in the new community). Some of them got banned too and came here. And some of us are still in the other group. It's just better for us (here)."

\section{Conclusions}

Even though the white moderators of The Playhouse made no explicit statements about racial segregation, their actions of actively policing and shutting down the discussion of race issues as they related to the community's interests formed a very strong and solid barrier for these members. It is worth pointing out that the members of the new group, created by those who felt excluded from The Playhouse, were explicit in their membership statement by noting that they were welcoming to people of different races. This created a different climate.

While the moderators in The Playhouse may not have consciously decided to exclude non-white members, their actions ultimately enforced a white-dominated environment where people of color felt unwelcome. The issue of race was seen as important to the majority of the members who were non-white, both in terms of their identity and their views of the toys they collected. But the white members did not see this issue as relevant, or indeed welcome.

There are some limitations to this research. As noted at the beginning, this group is almost entirely women, and there may be a gender bias in terms of the experiences within the group. A future study that looks at issues of gender segregation in online spaces would be very informative here. This study also focused on one particular community focused on one particular interest. Future research that examines if these practices exist in other online spaces would also provide a significant theoretical contribution.

The scholarly study of race online has come a long way since it began in the early 1990s. It is well understood at this point that the same issues that confront us in the face-to-face world have moved to the digital [43]. What we have demonstrated in this paper is that race is a very real and very significant aspect to how boundaries are created and enforced in an online space.

\section{References}

1. Sandvoss, C. Fans: The Mirror of Consumption; Polity Press: Cambridge, UK, 2005.

2. Kozinets, R.V. The field behind the screen: Using netnography for marketing research in online communities. J. Mark. Res. 2002, 39, 61-72.

3. Omi, M.; Winant, H. Racial Formation in the United States: From the 1960s to the 1990s, 2nd ed.; Routledge: New York, NY, USA, 1994.

4. Daniels, J. Race and racism in Internet studies: A Review and critique. New Media Soc. 2012, doi:10.1177/1461444812462849. Available online: http://nms.sagepub.com/content/early/2012/ 12/06/1461444812462849 (accessed on 22 January 2013). 
5. Feagin, J.R.; Elias, S. Rethinking racial formation theory: A Systemic-racism critique. Ethn. Rac. Stud. 2012, doi:10.1080/01419870.2012.669839. Available online: http:/www.tandfonline.com/ doi/full/10.1080/01419870.2012.669839 (accessed on 22 January 2013).

6. Bonilla-Silva, E. Racism without Racists: Color Blind Racism and the Persistence of Racial Inequality in the United States, 3rd ed.; Rowman and Littlefield: Lanham, MD, USA, 2012.

7. Feagin, J.R. Racist America: Roots, Current Realities, and Future Reparation; Routledge: New York, NY, USA, 2000.

8. Frankenberg, R. White Women, Race Matters: The Social Construction of Whiteness; University of Minnesota Press: Minneapolis, MN, USA, 1993.

9. Lenhart, A.; Rainie, L.; Fox, S.; Horrigan, J.; Spooner, T. Who's not Online; Pew Internet and American Life Project: Washington, DC, USA, 2000; Available online: http://pewinternet.org/ /media//Files/Reports/2000/Pew_Those_Not_Online_Report.pdf.pdf (accessed on 22 January 2013).

10. Zickuhr, K.; Smith, A. Digital Differences; Pew Internet and American Life Project: Washington, DC, USA, 2012; Available online: http://pewinternet.org/ /media//Files/Reports/2012/ PIP_Digital_differences_041312.pdf(accessed on 22 January 2013).

11. Gunkel, D.J. Second thoughts: Toward a critique of the digital divide. New Media Soc. 2003, 5, 499-522.

12. Everett, A. On cyberfeminism and cyberwomanism: High-tech mediations of feminism's discontents. Signs 2002, 30, 1278-1285.

13. Jenkins, H. Cyberspace and Race. Available online: http://www.technologyreview.com/ web/12797 (accessed on 28 February 2013).

14. Hall, S. Representations: Cultural Representations and Signifying Practices; SAGE: London, UK, 1997.

15. Grasmuck, S.; Marting, J.; Zhao, S. Ethno-racial identity displays on Facebook. J. Comput. Mediat. Commun. 2009, 15, 158-188.

16. Tynes, B.M.; Markoe, S.L. The role of color-blind racial attitudes in reactions to racial discrimination on social network sites. J. Divers. High. Educ. 2010, 3, 1-13.

17. Nakata, M.; Nakata, V.; Gardiner, G.; McKeough, J.; Byrne, A.; Gibson, J. Indigenous digital collections: An early look at the organisation and culture interface. Aust. Acad. Res. Libr. 2008, 39, 223-236.

18. Myers, K. Racetalk: Racism Hiding in Plain Sight; Rowman and Littlefield: New York, NY, USA, 2005.

19. Bimber, B. Measuring the gender gap on the internet. Soc. Sci. Quart. 2000, 81, 868-876.

20. Ono, H.; Zavodny, M. Gender and the internet. Soc. Sci. Quart. 2009, 84, 111-121.

21. Tuomi, I. Networks of Innovation: Change and Meaning in the Age of the Internet; Oxford University Press: Oxford, UK, 2002.

22. Irving, C.J. Community in cyberspace: Gender, social movement learning, and the internet. Adult Educ. Quart. 2011, 61, 262-278.

23. Shifman, L.; Lemish, D. Between feminism and fun(ny)mism: Analyzing gender in popular internet humor. Inf. Commun. Soc. 2010, 12, 870-891.

24. Pedersen, S.; Smithson, J. Mother with attitude-How the Mumsnet parenting forum offers space for new forms of Femininity to emerge online. Women's Stud. Int. For. 2013, 38, 97-106. 
25. Savicki, V.; Lingenfelter, D.; Kelley, M. Gender language style and group composition in internet discussion groups. J. Comp.-Mediat. Commun. 1996, 2. Available online: http://onlinelibrary.wiley.com/doi/10.1111/j.1083-6101.1996.tb00191.x/abstract (accessed on 21 April 2013).

26. Hemphill, L.; Otterbacher, J. Learning the Lingo? Gender, Prestige and Linguistic Adaptation in Review Communities. In Proceedings of the ACM 2012 Conference on Computer Supported Cooperative Work, Seattle, WA, USA, 11-15 February 2012.

27. Danet, B. Text as Mask: Gender, Play, and Performance on the Internet. In Cybersociety 2.0: Revisiting Computer-Mediated Community and Technology; Jones, S., Ed.; SAGE: London, UK, 1998.

28. Aries, E. Men and Women in Interaction: Reconsidering the Differences; Oxford University Press: Oxford, UK, 1996.

29. Diamond, N.; Sherry, J.F.; Muniz, A.M.; McGrath, M.A.; Kozinets, R.V.; Borghini, S. American Girl and the brand gestalt: Closing the loop on sociocultural branding research. J. Mark. 2009, 73, $118-132$.

30. Acosta-Alzuru, C.; Lester Roushanzamir, E. Everything we do is a celebration of you! Pleasant Company constructs American girlhood. Commun. Rev. 2003, 6, 45-69.

31. Acosta-Alzuru, C.; Kreshel, P.J. I'm an American girl...whatever that means: Girls consuming Pleasant Company's American Girl identity. J. Commun. 2002, 52, 139-161.

32. Medina, V.E. And that's What I Think Being an American Girl is all about! Girls' Reflections on American Girl and Contemporary American Girlhood. Ph.D. Thesis, University of Missouri, Columbia, MO, USA, 2012.

33. Marshall, E. Consuming girlhood: Young women, femininities, and American Girl. Girlhood Stud. 2009, 2, 94-111.

34. Stalp, M.C.; Williams, R.; Lynch, A.; Radina, M.E. Conspicuously consuming: The Red Hat society and midlife women's identity. J. Contemp. Ethnogr. 2009, 38, 225-253.

35. Rafaeli, S.; Ravid, G.; Soroka, V. De-Lurking in Virtual Communities: A Social Communication Network Approach to Measuring the Effects of Social and Cultural Capital. In Proceedings of the Annual Hawaii International Conference on System Sciences, Big Island, HI, USA, 5-8 January 2004. Available online: http://www.unhas.ac.id/ rhiza/arsip/jarkomsos/lurkers.pdf (accessed on 22 January 2013).

36. Hines, C. Virtual Ethnography: Modes, Varieties, Affordances. In The SAGE Handbook of Online Research Methods; Fielding, N., Lee, R.M., Blank, G., Eds.; SAGE: London, UK, 2008.

37. Acosta-Alzuru, M.C. The American Girl Dolls: Constructing American Girlhood through Representation, Identity, and Consumption. Ph.D. Thesis, University of Georgia, Athens, GA, USA, 1999.

38. Nakamura, L. Cybertypes: Race and Ethnicity on the Internet; Routledge: New York, NY, USA, 2002.

39. Nakamura, L. Digitizing Race: Visual Cultures of the Internet; University of Minnesota Press: Minneapolis, MN, USA, 2007.

40. Bobo, L.; Sidanius, J.; Sears, D.O. Racialized Politics: The Debate about Racism in America; University of Chicago Press: Chicago, IL, USA, 2000. 
41. Miller, K.D.; Fabian, F.; Lin, S. Strategies for online communities. Strat. Manag. J. 2008, 30, 305-322.

42. Villalpando, O. Self-segregation or self-preservation? A critical race theory and Latina/o critical theory analysis of a study of Chicana/o college students. Int. J. Qualit. Stud. Educ. 2003, 16, 619-646.

43. Nakamura, L.; Chow-White, P.A. Race after the Internet; Routledge: New York, NY, USA, 2011.

(C) 2013 by the authors; licensee MDPI, Basel, Switzerland. This article is an open access article distributed under the terms and conditions of the Creative Commons Attribution license (http://creativecommons.org/licenses/by/3.0/). 